\title{
Introduction to the special issue on recent advances and developments in atmospheric electricity
}

\author{
Cheng-Ling Kuo ${ }^{1, *}$, Alfred Bing-Chi Chen ${ }^{2}$, Rue-Ron $\mathrm{Hsu}^{3}$, and Lou-Chuang Lee ${ }^{4}$ \\ ${ }^{1}$ Institute of Space Science, National Central University, Taoyuan City, Taiwan \\ ${ }^{2}$ Institute of Space and Plasma Sciences, National Cheng Kung University, Tainan City, Taiwan \\ ${ }^{3}$ Department of Physics, National Cheng Kung University, Tainan City, Taiwan \\ ${ }^{4}$ Institute of Earth Sciences, Academia Sinica, Taipei City, Taiwan
}

Received 18 July 2017, Revised 19 July 2017, Accepted 21 July 2017

Keywords: ISUAL/FORMOSAT2, Transient luminous events (TLEs), Space electricity, Atmospheric electricity

Citation: Kuo, C.-L., A. B.-C. Chen, R.-R. Hsu, and L.-C. Lee, 2017: Introduction to the special issue on recent advances and developments in atmospheric electricity. Terr. Atmos. Ocean. Sci., 28, I-III, doi: 10.3319/TAO.2017.07.21.01

The special issue highlights the state of research efforts on the atmospheric electricity in Asia, particularly in Taiwan, China and Japan. In some ways, this can also be viewed as a commemorative issue for the ISUAL/FORMOSAT2 experiment, which officially ended its mission in July 2016. The first breakthrough on atmospheric electricity research in Taiwan was achieved through ground campaigns, including the investigations of transient luminous events (TLEs) near the vicinity of Taiwan (Su et al. 2002; Hsu et al. 2003) and gigantic jet (Su et al. 2003). From 2004 - 2016, the satellite mission of ISUAL (Imager of Sprite/ Upper Atmospheric Lightning) onboard the FORMOSAT2 satellite was conducted, and a few important results are reported in (Hsu et al. 2017; this issue). The ISUAL mission is a successful international cooperation between Taiwan, USA and Japan (Chern et al. 2003; Su et al. 2005; Chen et al. 2008). The past and current TLE scientific missions include the Mediterranean Israeli Dust Experiment (MEIDEX) sprite campaign onboard the space shuttle Columbia in 2003 (Yair et al. 2003), a Japanese micro satellite SPRITE-SAT (2010-) (Takahashi et al. 2010), the Japan mission Global Lightning and Sprite Measurements on Japanese Experiment Module (JEM-GLIMS) on the International Space Station (ISS) from 2011 (Sato et al. 2015, 2017), NASA Crew Earth Observation program (2011 - 2012) (Jehl et al. 2013), and the Iriss mission by Denmark's first astronaut, Andreas Mogensen on the ISS (Chanrion et al. 2017). The upcoming orbit missions including ASIM (AtmosphereSpace Interaction Monitor) (Neubert 2009) and TARANIS (Tool for the Analysis of RAdiations from lightNIngs and Sprites) (Farges et al. 2017). The ISUAL mission besides being a pioneer atmospheric electricity program, also is a

\footnotetext{
* Corresponding author

E-mail: clkuo@jupiter.ss.ncu.edu.tw
}

historic space platform dedicating to the study of TLEs in the middle atmosphere (Hsu et al. 2017; this issue).

In the special issues, papers are invited on the topics relevant to atmospheric electricity, especially for TLEs, thunderstorms, and lightning. In the special issue, Hsu et al. (2017) reviewed the important scientific results from the ISUAL mission, Chang et al. (2017) analyzed the sensitivity degradation of the Far Ultra-Violent (FUV) photometer, which affects the observed intensity of FUV emissions. Wu et al. (2017) revisited the occurrence rate of elves during El Niño and La Niña and extend the time series analysis to 25 November 2015. Lu et al. (2017a) examined the broadband $(<1 \mathrm{~Hz}$ to $30 \mathrm{kHz}$ ) lightning sferics associated with 395 sprites observed near North America by ISUAL in a 12-year period from 2004 - 2015. Sato et al. (2017) show the statistical results of TLEs in the JEM-GLIMS missions. Their innovative data analytical methods of nadir observation from ISS include: (1) extraction of relatively weak sprite emission from lightning emission, (2) a calculation of the intensity ratio between different photometer channels, and (3) an estimation of the charge moment change of the suspected sprite-producing CG discharge. For TLE ground campaign, Peng et al. (2017) showed the first coordinated observation on TLEs from space and ground, and Lu et al. (2017b) analyzed a recorded sprite spectrum by the slitless spectroimager in the 2016 Lulin Observatory ground campaign. Yang et al. (2017) showed TLEs ground observations in mainland China in 2012. This study found a very unusual and unique positive sprite event, which may be produced jointly by two distinct positive cloud-to-ground lightning flashes but separated by about $27 \mathrm{~km}$.

Lastly, we hope that this special issue, in some way, can serve as a catalyst for the future communication and cooperation of the atmospheric electricity community in Asia. 


\section{REFERENCES}

Chang, S.-C., R.-R. Hsu, H.-T. Su, A. B. Chen, C.-L. Kuo, J.-K. Chou, Y.-J. Wu, and K.-M. Peng, 2017: ISUAL Imager and far-ultraviolet spectrophotometer degradation. Terr. Atmos. Ocean. Sci., 28, 563-569, doi: 10.3319/TAO.2016.08.26.01. [Link]

Chanrion, O., T. Neubert, A. Mogensen, Y. Yair, M. Stendel, R. Singh, and D. Siingh, 2017: Profuse activity of blue electrical discharges at the tops of thunderstorms. Geophys. Res. Lett., 44, 496-503, doi: 10.1002/2016gl071311. [Link]

Chen, A.-B., C.-L. Kuo, Y.-J. Lee, H.-T. Su, R.-R. Hsu, J.-L. Chern, H.-U. Frey, S.-B. Mende, Y. Takahashi, H. Fukunishi, Y.-S. Chang, T.-Y. Liu, and L.-C. Lee, 2008: Global distributions and occurrence rates of transient luminous events. J. Geophys. Res., 113, doi: 10.1029/2008ja013101. [Link]

Chern, J.-L., R.-R. Hsu, H.-T. Su, S.-B. Mende, H. Fukunishi, Y. Takahashi, and L.-C. Lee, 2003: Global survey of upper atmospheric transient luminous events on the ROCSAT-2 satellite. J. Atmos. Sol.-Terr. Phys., 65, 647-659, doi: 10.1016/s1364-6826(02)00317-6. [Link]

Farges, T., E. Blanc, P. Hébert, F. Le Mer-Dachard, K. Ravel, and S. Gaillac, 2017: MicroCameras and Photometers (MCP) on board TARANIS satellite. Geophys Res Abstr., 19, EGU2017-6024.

Hsu, R.-R., H. T. Su, A. B. Chen, L. C. Lee, M. Asfur, C. Price, and Y. Yair, 2003: Transient luminous events in the vicinity of Taiwan. J. Atmos. Sol.-Terr. Phys., 65, 561-566, doi: 10.1016/s1364-6826(02)00320-6. [Link]

Hsu, R.-R., H.-T. Su, A. B.-C. Chen, and C.-L. Kuo, 2017: Selected results from the ISUAL/FORMOSAT2 mission. Terr. Atmos. Ocean. Sci., 28, 525-544, doi: 10.3319/TAO.2016.08.23.01. [Link]

Jehl, A., T. Farges, and E. Blanc, 2013: Color pictures of sprites from non-dedicated observation on board the International Space Station. J. Geophys. Res., 118, 454-461, doi: 10.1029/2012ja018144. [Link]

Lu, G., S. A. Cummer, A. B. Chen, F. Lyu, D. Li, F. Liu, R.-R. Hsu, and H.-T. Su, 2017a: Analysis of lightning strokes associated with sprites observed by ISUAL in the vicinity of North America. Terr. Atmos. Ocean. Sci., 28, 583-595, doi: 10.3319/TAO.2017.03.31.01. [Link]

Lu, M.-R., P.-Y. Chen, C.-L. Kuo, C.-C. Chou, B.-X. Wu, S. Abe, H.-T. Su, R.-R. Hsu, S.-H. Wang, N.-H. Lin, and L.-C. Lee, 2017b: Recent work on sprite spectrum in Taiwan. Terr. Atmos. Ocean. Sci., 28, 625-636, doi: 10.3319/TAO.2016.08.26.02. [Link]

Neubert, T., N. B. Crosby, T.-Y. Huang, and M. J. Rycroft, 2009: ASIM - an Instrument Suite for the Internation- al Space Station. AIP Conference Proceedings, 1118, 8-12, doi: 10.1063/1.3137718. [Link]

Peng, K.-M., R.-R. Hsu, H.-T. Su, A. Chen, J.-K. Chou, S.C. Chang, Y.-J. Wu, C.-L. Hung, I.-C. Yang, and S.-H. Tsai, 2017: Transient luminous event coordinated observations using FORMOSAT-2 satellite and Taiwan sprites campaign. Terr. Atmos. Ocean. Sci., 28, 597608, doi: 10.3319/TAO.2016.09.21.03. [Link]

Sato, M., T. Ushio, T. Morimoto, M. Kikuchi, H. Kikuchi, T. Adachi, M. Suzuki, A. Yamazaki, Y. Takahashi, U. Inan, I. Linscott, R. Ishida, Y. Sakamoto, K. Yoshida, Y. Hobara, T. Sano, T. Abe, M. Nakamura, H. Oda, and Z.-I. Kawasaki, 2015: Overview and early results of the Global Lightning and Sprite Measurements mission. J. Geophys. Res., 120, 3822-3851, doi: 10.1002/2014jd022428. [Link]

Sato, M., T. Adachi, T. Ushio, T. Morimoto, M. Kikuchi, H. Kikuchi, M. Suzuki, A. Yamazaki, Y. Takahashi, R. Ishida, Y. Sakamoto, K. Yoshida, and Y. Hobara, 2017: Sprites identification and their spatial distributions in JEM-GLIMS nadir observations. Terr. Atmos. Ocean. Sci., 28, 545-561, doi: 10.3319/TAO.2016.09.21.02. [Link]

Su, H.-T., R.-R. Hsu, A. B.-C. Chen, Y.-J. Lee, and L.C. Lee, 2002: Observation of sprites over the Asian continent and over oceans around Taiwan. Geophys. Res. Lett., 29, 3-1-3-4, doi: 10.1029/2001GL013737. [Link]

Su, H.-T., R.-R. Hsu, A.-B. Chen, Y.-C. Wang, W.-S. Hsiao, W.-C. Lai, L.-C. Lee, M. Sato, and H. Fukunishi, 2003: Gigantic jets between a thundercloud and the ionosphere. Nature, 423, 974-976, doi: 10.1038/ nature01759. [Link]

Su, H.-T., R. Hsu, A. B. Chen, L. Lee, S. B. Mende, H. U. Frey, H. Fukunishi, Y. Takahashi, and C. Kuo, 2005: Key results from the first fourteen months of ISUAL experiment, AGU Fall Meeting Abstracts, 11,01.

Takahashi, Y., K. Yoshida, Y. Sakamoto, and T. Sakamoi, 2010: SPRITE-SAT: A University Small Satellite for Observation of High-Altitude Luminous Events. In: Sandau, R., H.-P. Roeser and A. Valenzuela (Eds.), Small Satellite Missions for Earth Observation: New Developments and Trends, Springer Berlin Heidelberg, Berlin, Heidelberg, 197-206, doi: 10.1007/978-3-64203501-2_18. [Link]

Wu, Y.-J., R.-R. Hsu, A. B.-C. Chen, H.-T. Su, S.-C. Chang, J.-K. Chou, Y.-J. Lee, and K.-M. Peng, 2017: Revisiting oceanic elves and lightning occurrence rate during El Niño and La Niña episodes over a 10-year time frame. Terr. Atmos. Ocean. Sci., 28, 571-581, doi: 10.3319/TAO.2016.07.28.01. [Link]

Yair, Y., C. Price, Z. Levin, J. Joseph, P. Israelevitch, A. Devir, M. Moalem, B. Ziv, and M. Asfur, 2003: Sprite observations from the space shuttle during the 
Mediterranean Israeli dust experiment (MEIDEX). $J$. Atmos. Sol.-Terr. Phys., 65, 635-642, doi: 10.1016/ s1364-6826(02)00332-2. [Link]

Yang, J., G. Lu, N. Liu, M. Sato, G. Feng, Y. Wang, and
J.-K. Chou, 2017: Sprite possibly produced by two distinct positive cloud-to-ground lightning flashes. Terr. Atmos. Ocean. Sci., 28, 609-624, doi: 10.3319/ TAO.2016.07.22.01. [Link] 